\title{
RE-URB/ARCH: urban and architectonic regeneration strategies: sustainability models
}

\author{
G. Mondaini, C. Carluccio \& R. Panariello \\ Marche Polytechnic University, Ancona, Italy
}

\begin{abstract}
Urban areas cause a set of environmental challenges, which come from the consumption of natural resources and the generation of waste and pollution. These aspects contribute to the development of social and economic imbalance, which continues to grow while demanding new solutions. Therefore urban planning and architecture needs a new and flexible approach, introducing methods and techniques which can adjust to diverse situations and imply different solutions. Architectural design assumes a central role, more relevant than the technological aspects or performances: the design begins from the urban scale, reaches the architectural composition level, for shapes and orientations, and the restoration of the existing building heritage, and finally incorporates also the technological aspects. It allows us to avoid globalizing space solutions and architecture languages, towards an approach that focuses on the specific context.

The UNIVPM DICEA department has developed two different scientific researches aiming to detect sustainable models and methods of intervention within the modern city: a) a regulation to evaluate the energetic and environmental quality of Public Residential Buildings for the city of Civitanova Marche; b) a structural document finalized to urban instruments' innovation, for what concerns the city of Fabriano.

These two levels have two factors in common: 1) Both focus on cities in a transitional stage; places that express the inadequacy of modern urban planning's techniques involving sustainability, which pursue the dynamics of a territory's transformation but fail to manage them. 2) Both are based on the same procedure used to methodize the suggested solutions; buildings' features become strategic, and so do their orientation and volume, in order to define the energy performance levels. It consists of the invention of a table of combination sets for urban and architectural solutions, which shows all the steps required, from the administrative system to the technical and design guidelines.
\end{abstract}


For what concerns Civitanova Marche, the Regulation has allowed us to study sustainability matters and develop techniques for the intervention, while considering the public city as the engine of urban regeneration strategies. It suggests city plans and building volumes conceived to be, "by shape", sustainable. In this way architecture's quality becomes again the main aspect of urban planning, while encouraging an integrated approach to design which suggests methods to analyze the context, defines techniques and actions for a sustainable approach to planning and design, determines the results to achieve and the resources to stimulate and value performance and architectural quality.

In regard to Fabriano, the structural document, by using the regeneration of the existing elements, enables us to develop the design of a new city model, able to collect and activate new investments while assuring, without further expansions, a concrete environmental sustainability that evolves around urban valorization processes and the city's spatial and property heritage. Therefore it is an urban plan that, during and beyond the crisis, combines economic feasibility and sustainability successfully, directing them towards limited soil exploitations, ecological balance, environmental comfort, energy savings, efficient transportation system, and care of the public city. Such process concerns mainly ten proposals of "micro-cities" relating to crucial places in Fabriano and defines a procedure that develops a combined means of competitive urban planning. Keywords: urban regeneration, integrated process, competitive urban planning, income capture, urban densification, building retrofitting, best available building.

\section{Introduction}

\subsection{Preliminary remarks}

The principle of sustainability in territorial government actions is a topic that has already been closely examined in almost all its aspects; the results of this research have one factor in common: the centrality of a careful design process, from the wider area to the urban scale, and from the architectural project to the plant engineering project. This is the key to understanding the sustainability chain. Within a perspective for a diverse (and balanced) relationship between the city and natural areas there lies a challenge: that of recovering, re-establishing, regenerating and converting areas where decentralisation of production and the low-density housing model in recent decades have consumed natural and agricultural land (brownfield land). This has created an expansive city model that is completely unsustainable, due to its exponential need for services and general consumption of economic and energy resources. In recent years in Italy, 100 hectares have disappeared beneath concrete each day, equivalent to an area 50 times the size of Piazza del Duomo in Milan (AA.VV [1]). This is the result of a land development which in recent decades has assumed a dynamic incommensurate with real housing needs (double that of France and Germany) (AA.VV [2]). For Italy, therefore, the re-launching of a planning culture focussed on putting in place a new "urban planning" modality for the creation of 
green spaces, with the inclusion of biological and organic spaces in more densely built urban areas and promotion of vegetation on both vertical and horizontal surfaces, seems indispensable (Boeri [3]). Basically, there is a need to promote the establishment of proper green belts (AA.VV [4]). The growing demand for redevelopment, in an ecological and cost-containment framework, now involves planning, on both the urban scale as well as the building scale, with complex procedures in which certain basic principles need to be taken into account: rationalisation of housing locations (in terms of land use, rational urban planning and ecological balance), sufficient attention to the public city, a passive reduction in energy consumption, an active production of renewable energy and lastly the closure of cycles (for example, that of water) (AA.VV [5]).

This need to address the urban planning and building deterioration of the city and the territory, combining research with the indispensable paradigm of sustainability, is providing an extraordinary opportunity for experimenting with the implementation of procedures, methods, models and techniques:

- administrative procedures to facilitate closer and balanced interaction between public and private sectors, and to thereby address the situation of crisis;

- planning, operational and technical methods to implement the planning choices to be adopted for the redesign of built-up and open spaces;

- cultural models to replicate and adopt;

- techniques and applications of the best available energy-saving technologies.

The guiding strategies for sustainable planning should take into account:

- the organisation and balance of the urban functional mix, favouring the combination of functions within spatially contained areas, with reduction of the distances required for travel between home and work and in free time;

- the characteristic features and identity of each place;

- green spaces and the conservation/development of natural reserves within the urban system;

- the of the localisation of infrastructures and the containment of private mobility by maximising collective and/or bicycle and pedestrian transport;

- unused complexes and sections and the connected deterioration of derelict areas;

- the reuse of rainwater on an urban design scale;

AA.VV [6]. These sustainable planning strategies can be combined with planning choices which, although intentionally directed towards land consumption, build or redefine an urban environment with adequate public spaces, with an adequate ratio of voids to solids and built to unbuilt spaces, which may consume land but includes compact green areas (Pareglio [7]). We should therefore view the term land consumption in the widest sense, including the reconnection of existing urban fabric and the redefinition of boundaries. We need to invert the settlement trend from the extra-urban territory to within the urban area, while safeguarding areas such as nature reserves, by relying on:

- the provision of effective environmental compensation;

- implementation of the capacity to remove atmospheric pollutants;

- improvement of the urban microclimate, reducing heat islands;

- the guarantee of a better acoustic climate;

- implementation of environmental and recreational, and therefore social benefits. 
In addition to urban planning strategies, it is indispensable to develop research on the construction level. Achieving the objective of a sustainable city requires, even more than the unquestionable need for research into new construction forms and techniques, projects that are capable of reinterpreting the large mass of existing construction that fails to meet the minimum requirements of environmental comfort. Planning in modern times has produced buildings that are now no longer sustainable, both in terms of energy consumption and that of the quality of spaces, particularly in the case of housing. This is the result of a radical detachment of design theories, which in those years were often too ideological, from the problems connected with control of energy, spatial and functional issues. Designing the new city within the city requires the regeneration of urban spaces and existing buildings, providing them with characteristics and performance levels capable of meeting both current legislative requirements regarding energy and seismic hazard, and the spatial and functional needs of contemporary living.

The research activity approach is based on the concept of "retrofitting" existing buildings, which rejects the idea of demolition and rebuilding in favour of innovative methods for re-use, focussing on the development of methods for intervening on existing constructions, based on three main operations: replanning, transforming and upgrading/implementing.

\section{Replanning}

Ground floors, roofs and facades of buildings in modern cities, which were often built too rapidly, assume a very important role in the idea of total building regeneration, starting from the re-evaluation of the functional design programme and the relationship with the surrounding city: this provides real support for volumetric, functional and linguistic regeneration and energy-control activities.

\section{Transforming}

Possible physical transformations can be applied to the building, starting from its existing characteristics. Planning is aimed at grasping hidden potentials within constructed spaces, seeking to enhance them with targeted, surgical interventions geared towards maintaining what already exists and reusing it in a more efficient and effective way.

The typological standardisation common to construction, particularly public buildings, on which we are required to work, allows us to formulate "standard operations" that can be applied to buildings: opening frames, enlarging, place on, surfacing and connecting.

\section{Upgrading/implementing}

Upgrading refers to the improvement of the building's efficiency from a static and energy perspective. The compliance of buildings with seismic safety measures, the durability of materials, and energy and consumption issues are fundamental aspects to address in order to achieve the objective of a safe and 
sustainable city. Particular attention can be given to the use of nanotechnologies in building retrofitting operations, due to their great potential in terms of performance improvement and their low level of invasiveness in operational and intervention terms.

The research carried out has defined areas for urban planning and spaces within the recent variegated urban structure, suitable for "homogeneous regeneration units" known as micro-cities. These are intended to enhance the pluralistic and polycentric character of the recently designed city, stimulating recovery projects capable of identifying and proposing various modalities of use for the city. It is important that these proposals consider: "relationship speed", through the new and necessary infrastructure connections and, at the same time, "slowness" and "proximity", through the proposed local centres. Particular attention has been given to this latter collective subsystem, which allows the development of the concept of micro-centrality, created from a desire to densify unresolved and degraded spaces that are potentially attractive, relating them also with the nearest environmental and ecological systems.

The densification and regeneration of spaces and existing volumes is based on the need to include complimentary dialogue/integration between urban planning/design and issues of energy sustainability in the objectives and strategic preview activities for the city. This is done through identification of the technical/architectural processes necessary for recovery of the existing building heritage (in terms of energy control and related interventions of a bioclimatic nature). A further aspect of the research carried out concerns the development of new parts of the city, particularly intended for public housing, following the same environmental sustainability objectives. Territorial transformation criteria have been defined to ensure that the application of Implementation Plans for the development of new public housing areas is compatible with environmental protection and sustainability objectives. This process has led to the drafting of the Plans and developed territorial and environmental surveys for the purpose of evaluating the transformations made under the new provisions, through sector analysis of environmental, water and energy resources, of artificial environmental risk factors and of local production.

\subsection{The study cases}

The following case studies can be presented to specifically illustrate the topics described above:

-Regulations for evaluating the energy and environmental quality of buildings in public housing areas, and incentive procedures in conformity with the rules of the Local Strategic Plan of the Municipality of Civitanova Marche;

-Structural document for the innovation of the Municipality of Fabriano's urban planning instruments in order to identifying modalities for the urban and architectural regeneration of the existing city. 


\section{Civitanova Marche}

Civitanova, a city of approximately 40,000 inhabitants on the mid-Adriatic coast, is the centre of a production district specialised in the processing of hides and leather, with footwear as its specialist product.

\subsection{The research: the implementation plans and the regulations}

The Municipality of Civitanova Marche has assigned a preparatory role to the Marche Polytechnic University for the drafting of the Implementation Plans for public housing. The purpose is to develop implementation planning in which the usual separation between the urban environment, the construction level and technical and performance characteristics, particularly in regard to energy and environmental sustainability, is eliminated. For this purpose, regulations have been drawn up for the evaluation of the energy and environmental quality of buildings. Producing intervention strategies starting from the public city, as possible regeneration systems, means to develop issues that are now part of a broader reflection on contemporary city planning:

- restoration of architectural, spatial and social quality to the centre of urban planning and construction activities;

- making buildings and spaces sustainable in terms of energy.

Issues such as land consumption, mobility, air quality, and the energy consumption of buildings can and must become an occasion for creating and identifying the parameters for a new level of quality. This would not just concern formal and functional aspects regarding architecture and the quality of life, but also technical and energy and environmental sustainability aspects. The study supports an integrated approach to design, which includes analysis of the climatic and environmental characteristics of the sites involved, encouraging savings in energy resources, intervention on urban and architectural structures and the avoidance of incongruent, chaotic and excessively technical overlapping.

The regulations propose methods for analysis of the context, outline relevant techniques and operations for a sustainable approach to the planning and design, and determine the results to be achieved and the initiatives to be incentivised in order to enhance the performance and architectural quality of the new works.

The steps laid down by the regulations include:

- the underlying criteria for the assignment of incentives;

- the requirements to be met during the design phase;

- the drawings to be prepared;

- the modalities for verifying the formulated hypotheses on completion of the works.

For the areas covered by the implementation plans, the regulations provide regulatory and design indications starting from the work of analysis of the areas themselves. 


\subsection{Metaprojectual indications}

The metaprojectual indications concretise all the analyses and planning and design activities. The meta-projects for the various sectors contain provisions, some which are prescriptive while others are guidelines, to guarantee the best use of natural resources as well as the prevention of environmental risks. The metaproject drawings are organised in order to allow an effective comparison between the existing structure, the respective analysis and the proposed solution. An initial part of the drawings contains land buildability prescriptions and indices, an extract of the ground plan and the acoustic zoning, analysis of the prevailing winds and orientation, as well as the placement of the area in the broader context of the city. A second part contains the new ground plan and tables containing the verification of compliance with the minimum urban planning requirements necessary to support any increase in volume due to the granting of planning permission. The expediency of surface increases was guided by the conviction that the quality of the buildings, expressed both in terms of energy and environmental sustainability, as well as architectural quality, must always be prioritised and promoted.

\subsection{Consideration of the effects}

It is a commonly held opinion that the regulatory and numerical control of territorial planning has not produced the intended results; city planning control through planning standards has proved inadequate for dealing with fast urban dynamics. A more promising plan for the future, currently at an embryonic stage, is represented by the Strategic Environmental Evaluation, which lends itself to a control (both in the drafting phase and particularly during the audit phase, or monitoring of the results of the plans/designs) that is focused mainly on the city's actual performance capacities, rather than a merely numerical control (Panariello and Michelangeli [9]).

Consideration of the environmental effects caused by meta-projects has therefore been developed in parallel to the planning phase, together with the audit/feedback procedures, using a "presumed environmental pressure calculation" model to assess settlement pressure on the territory and on features of environmental quality. The extent of the variations produced by the metaprojectual forecasts was evaluated by verifying the impact produced on the air, water and soil. Forms of mitigation and compensation useful for environmental rebalancing and design solutions were introduced on this basis to ensure a high level of energy and environmental quality, safety and work standards. Each of the indicators (water, air, soil, ecosystem, management of resources, energy and traffic) was given a level of significance, based on a combined examination of the frequency, duration, reversibility and probability of each of the considered effects and of the degree of vulnerability or value of the area in which the effect occurs. On the basis of the data and the plano-volumetric organisation of the area, the impacts produced by settlement have been evaluated in terms of:

- atmospheric pollution due to private vehicle traffic based on the presumed number of resident drivers; 
- atmospheric pollution due to commercial vehicle traffic based on the total road surface;

- atmospheric pollution due to heating based on the per capita thermal energy requirements for heating and domestic hot water;

- production of wastewater by the settlement;

- water requirements of the commercial settlement;

- waste production (urban solids and similar waste).

\subsection{Guidelines for efficient energy use and the prioritising of renewable energy sources}

The indications contained in the Regulations propose and promote a concept of architecture that is in close relationship with the surrounding environment. The building must be understood as a complex system capable of energy exchange with the exterior and in contrast with the "sealed house" model. There is therefore a desire to communicate an alternative vision of planning which, through a conscious choice of forms, techniques and materials, is aimed at safeguarding the environment, a rational use of resources, use of the potential offered by the site and the psychophysical wellbeing of the inhabitants. Some principal strategies include:

- attention to the inhabitants, each sustainability choice and action is at the service of the citizen, who remains the primary point of reference;

- attention to the location, because sustainable construction is necessarily related to the intervention site and its characteristics;

- attention to the form of the architecture, both in terms of building quality, and as an element capable of interacting with the climate characteristics.

- attention to the construction process through safeguarding of the environment both during and after the construction of an architectural project.

The project is understood as a synthetic process, which aside from involving typically disciplinary matters: architecture, urban planning, landscaping and environmental protection, must also address the definition of objectives, and the identification and verification of solutions in relation to the sustainable project. In order to establish urban planning in a correct and complete manner, indications are provided in the regulations regarding the building organism and its surroundings, and general technical-construction, typological and plant engineering criteria. A basic and strategic role is assumed by the planovolumetrics proposed by the regulations for each area of intervention. A significant factor indicated by the design approach, from a composite and typological perspective, is the fluid role of the open and public space as the link between small buildings, in an alternate and non-uniform arrangement, which is thereby capable of creating an active relationship with the environment and its essential factors, the sun, wind, etc.; finally, it also favours typologicaldistributive factors that allow double exposure of houses for proper cooling of rooms. 


\section{Fabriano}

Fabriano, a city of approximately 32,000 inhabitants on the slopes of the Marchigian Apennines, is the centre of a production district characterised by companies mainly connected with the domestic appliance industry. There is a significant presence of large-scale companies, most of which are involved in the final stages of manufacturing production. In development terms, this characteristic has meant a significant exposure to the negative factors of the economic and financial crisis in recent years.

\subsection{Public-private partnership: beyond the rigidity of the local strategic plan}

Due to the effect of the economic crisis, the scenario is characterised by a scarcity of public resources and a progressive reduction of available private funding. In this situation, planning instruments and local government are forced to rapidly consider the following issues, and in a new way:

- strategies aimed at a more aware and responsible use of the territory,

- efficient use of economic, environmental and energy resources,

- moderation and efficiency in urban and infrastructure projects,

- development of public-private partnerships, with new forms of collaboration between various parties and interest groups and with an involvement of operators.

Public administration and urban planning regulations are faced with a difficult challenge: that of developing and sustaining the governance of a new social and urban model, the creation of a city project that is capable of not just attracting and activating new investments but, above all, of changing the behaviour of the community and of companies in order to ensure a more real sustainability in processes of use and the respect of common goods. This is brought about through integrated policies and planning aimed at:

- the containment of land consumption,

- ecological balance, environmental comfort and energy saving,

- the efficiency and effectiveness of the transport system,

- care of the existing public city as a precious common good.

It is necessary, however, to define the strategic aspects that need to be wholly or partially financed by local and other public funds, through the selection of true priorities to create a strategic and shared programme. In order to gather private resources, it is necessary to address the issues connected with the use, on behalf of the public, of part of the urban real estate revenue as an economic surplus that urban planning transformations produce in the urban economy.

\subsection{The crisis and containment of land consumption: the capacity to demolish and build on built-up areas}

The economic and urban crises in Italy are in fact the product of the same mechanism. The city of Fabriano is not immune to this recession, which needs to be faced without further consumption of "greenfield land", concerning itself instead with working on the part of the city identified as "brownfield land", 
degraded and derelict areas and city sites "under demolition". This requires a greater structuring of land and buildings, giving value to existing buildings and, in particular, the "void" between blocks of construction that provides a resource for new design opportunities in terms of urban, social and environmental quality.

\subsection{The microcity for urban regeneration}

One priority is to bring the need for architecture in planning to the centre of the various discussions and to particularly highlight its capacity to improve the quality of life. The absence of a widespread design culture on all levels in Italy is evidence of the decline of the relationship between architecture, territory and society, which was always present in other moments of our history. The need exists for the reconstruction of an architectural planning production chain, through programmes in close contact with the real situation, wherever credible and sustainable transformation operations are required (Mondaini [10]). The area of intervention, the only one sustainable for the modern city, is its "existing mass": the city must review its spaces through extraordinary maintenance that builds on areas that are already built-up. An increasingly used term to best express this new attention towards the existing city is "regeneration". Good regeneration practices, capable of combining densification with a new design of open spaces, are those in which the necessary convergence between institutions and investors prevails. This involves public governance of ideas and above all a "creative" use of economic interests together with an ethical approach to the concept of "income levelling". The strategy and the creation of small centres, which we have called "microcities", within the more complex magnitude of the city require architecture that is capable, through an aesthetic, spatial and functional diversity, of reproducing "the city within the city". This can stimulate reactivation through instruments capable of producing synergy and the right balance between public and private interests, which are no longer in opposition.

The ten microcity proposals drawn up involve places of critical importance in a consolidated Fabriano: places that have lost their identity or for which one needs to be identified in this phase of transition. The quality for the proposals will be:

1. substantial preservation of the character of the existing city wherever its design is recognisable and, on the other hand, a new layout where the original design has been lost, with an ordering principle that is attentive towards environmental sustainability;

2. the possibility of demolition and reconstruction of buildings that are critical for architectural and urban quality, safeguarding those of particular historic and architectural interest;

3. flexibility regarding the designated use of buildings, stimulating variety and mixed functionality;

4. an increase in construction density, particularly in areas that are degraded, have lost their function or are unused, as a tool to reduce and concentrate services and urbanisation, with a significant reduction in consumptions;

5. a rebalance of functions between the centre and areas surrounding the consolidated city, with a revitalisation of the public city, and its places;

6. emphasis on the identities of the individual districts; 
7. an increase in accessibly priced housing, without sacrificing quality;

8. an incentive to encourage the presence of workers, including skilled workers and those of the propulsive services industries;

9. protection of monumental and landscape environments;

10. a significant restructuring operation on the existing building heritage to bring buildings in line with thermal control requirements, in order to pursue a new model of energy sustainability.

\subsection{Realisation instruments: innovating with a competitive model for sustainable urban planning}

A procedure has been defined for the transformation of areas in which urban regeneration is considered most necessary, together with a combined competitive urban planning instrument. This is intended to respond to the need to transfer a share of the land income to public interest for collective needs, transforming it into an opportunity to be governed in order to obtain an increase in quality, environmental efficiency and social attention expectations. This instrument, which we have called "Deferred Planning", should be implemented with a procedure that subordinates the transformations and buildability to the offer of:

- creation of public spaces, infrastructure, car parks and urban green spaces to improve environmental conditions;

- conferral of collective facilities to the public (e.g.: school buildings);

- conferral of social housing to the Municipality;

- a high overall quality of buildings, in view of effective thermal performance and energy sustainability.

These are elements that have been identified through a process of analysis of the city's needs, and those of its specific parts, and are referred to as project invariants. Having chosen the areas that are potentially respond to the problems that were initially identified, we then proceed with the second phase, which is competitive and comparative, involving the parties proposing regeneration actions. Only at this point is the actual legal attribution of the urban planning provisions reached, thereby linked to the proposals considered most valid in terms of collective needs, particularly the reduction of consumptions and the increase of environmental quality. In particular, the legal attribution of the provisions, in the current Zoning Variance, should be granted as a result of a process of evaluation of the best transformation proposal, valued in all its qualitative and quantitative parameters, which are established a priori, to reduce the use of discretionary power as much as possible.

The Municipality itself will launch a public tender phase in which the various parameters will be emphasised in view of priority needs. The competitive process resulting from this will place all the areas potentially suitable for regeneration into competition, with no privileged positions when the call for tenders is issued. Offers will be formulated by allocating strategic resources to attain the levels of quality specified by the Municipality in the tender.

The actions to be implemented to stimulate urban regeneration are recognition of the areas, identification of objectives and the definition of an Operational 
requalification programme in the form of one or more specific Detailed Implementation Plans, and should include:

- delimitation of the areas, the urban structure, intended uses, and building and urban planning indices.

- The implementation methods for the transformation interventions.

- The definition and localisation of territorial endowments as well as landscaping and ecological- environmental requalification interventions.

- localisation of public works and services and those of public interest.

- Measures aimed at implementing and incentivising energy saving and the use of renewable sources.

- An outline of the agreements to be drawn up with the operators.

- The criteria for any compensation and/or adjustment to be adopted.

The tender procedure proposed for Fabriano, organised in the form of microcity meta-projects, will be aimed at achieving the greatest return of public utility through private interventions, always as part of the outlined strategic scenario. The prior approval of Regulations defining the criteria for determination of the prevalence of public interest is therefore necessary, also considering, among other aspects, increase in land value following any urban planning changes.

Planning permission could be awarded to those who present the most worthy proposal in terms of social-environmental value, public benefit from the interventions and technical-architectural quality, within the minimal project framework proposed in the individual areas of urban regeneration. With this system, resources can be obtained for assignment to the community according to structural and logical rather than occasional modalities, due in part to the transfer of a share from the land income. In this way, the architectural quality and energy sustainability, as well as the environmental quality and coherence of the proposals, cease to be vague objectives, resolved only through unforeseeable incentives, and become the natural result of a procedure that is transparent, flexible and above all, repeatable.

\section{References}

[1] AA.VV., Osservatorio Nazionale Sui Consumi Di Suolo INU, Politecnico di Milano, Legambiente, 2009.

[2] AA.VV. Urbanistica Informazioni 238, INU Edizioni 2011.

[3] S. Boeri, L'anticittà, Laterza, 2011.

[4] AA.VV., The plan, urban development, Centauro, 2011.

[5] AA.VV., Città pubbliche: linee guida per la riqualificazione urbana, Bruno Mondadori, 2009.

[6] AA.VV. Eco-sostenibilità del progetto, AREA, 2009.

[7] S. Pareglio, Atti XXVI Congresso INU "Il nuovo piano", 2009.

[8] B. Secchi, Come ripensare il progetto urbano, Casabella, 2011.

[9] R. Panariello G. Michelangeli, La VAS del Piano TPL della Provincia di Ancona, Urbanistica Dossier 88, INU Edizioni, 2006.

[10] G. Mondaini, Microcities, Alinea, 2011. 